\title{
Incorporating a prediction of postgrazing herbage mass into a whole-farm model for pasture-based dairy systems
}

\author{
P. Gregorini, ${ }^{* 1}$ J. Galli,† A. J. Romera, ${ }^{*}$ G. Levy, ${ }^{*}$ K. A. Macdonald, ${ }^{*}$ H. H. Fernandez, $\ddagger$ and P. C. Beukes \\ *DairyNZ, Private Bag 3221, Hamilton 3240, New Zealand \\ †Facultad de Ciencias Agrarias, Universidad Nacional de Rosario, Zavalla S2125ZAA, Argentina \\ łInstituto Nacional de Tecnología Agropecuaria, Departamento de Producción Animal, Balcarce 7620, Argentina
}

\section{ABSTRACT}

The DairyNZ whole-farm model (WFM; DairyNZ, Hamilton, New Zealand) consists of a framework that links component models for animal, pastures, crops, and soils. The model was developed to assist with analysis and design of pasture-based farm systems. New (this work) and revised (e.g., cow, pasture, crops) component models can be added to the WFM, keeping the model flexible and up to date. Nevertheless, the WFM does not account for plant-animal relationships determining herbage-depletion dynamics. The user has to preset the maximum allowable level of herbage depletion [i.e., postgrazing herbage mass (residuals)] throughout the year. Because residuals have a direct effect on herbage regrowth, the WFM in its current form does not dynamically simulate the effect of grazing pressure on herbage depletion and consequent effect on herbage regrowth. The management of grazing pressure is a key component of pasture-based dairy systems. Thus, the main objective of the present work was to develop a new version of the WFM able to predict residuals, and thereby simulate related effects of grazing pressure dynamically at the farm scale. This objective was accomplished by incorporating a new component model into the WFM. This model represents plant-animal relationships, for example sward structure and herbage intake rate, and resulting level of herbage depletion. The sensitivity of the new version of the WFM was evaluated and then the new WFM was tested against an experimental data set previously used to evaluate the WFM and to illustrate the adequacy and improvement of the model development. Key outputs variables of the new version pertinent to this work (milk production, herbage dry matter intake, intake rate, harvesting efficiency, and residuals) responded acceptably to a range of input variables. The relative prediction errors for monthly and mean annual residual predictions were 20 and 5\%, respectively. Monthly predictions of residuals had a line

Received August 6, 2013.

Accepted April 5, 2014.

${ }^{1}$ Corresponding author: Pablo.Gregorini@dairynz.co.nz bias $(1.5 \%)$, with a proportion of square root of mean square prediction error (RMSPE) due to random error of $97.5 \%$. Predicted monthly herbage growth rates had a line bias of $2 \%$, a proportion of RMSPE due to random error of $96 \%$, and a concordance correlation coefficient of 0.87 . Annual herbage production was predicted with an RMSPE of 531 ( $\mathrm{kg}$ of herbage dry matter/ha per year), a line bias of $11 \%$, a proportion of RMSPE due to random error of $80 \%$, and relative prediction errors of $2 \%$. Annual herbage dry matter intake per cow and hectare, both per year, were predicted with RMSPE, relative prediction error, and concordance correlation coefficient of 169 and $692 \mathrm{~kg}$ of dry matter, 3 and 4\%, and 0.91 and 0.87 , respectively. These results indicate that predictions of the new WFM are relatively accurate and precise, with a conclusion that incorporating a plant-animal relationship model into the WFM allows for dynamic predictions of residuals and more realistic simulations of the effect of grazing pressure on herbage production and intake at the farm level without the intervention from the user.

Key words: dairy system model, simulation, grazing management

\section{INTRODUCTION}

The DairyNZ whole-farm model (WFM; DairyNZ, Hamilton, New Zealand; Beukes et al., 2008) consists of a framework that links component models for animal, pastures, crops, and soils. This model was developed to assist with analysis and design of pasture-based farm systems and experiments requiring system interactions over multiple spatial and temporal scales. New and revised component models can be added to the WFM, keeping the model flexible and up to date. Two of the main components models in the WFM simulate cow digestion, metabolism, and production [Molly cow model; Baldwin (1995)], and herbage growth (Romera et al. 2009).

The WFM predicts herbage regrowth after defoliation events. In WFM, as in the field, these responses are a function of herbage depletion [i.e., level of post- 
grazing herbage mass (residuals); Lee et al. 2007, 2008] and other factors, such as climate, soil characteristics, and fertilization. In the field, the level of residuals is directly related to grazing pressure, which is defined as the relationship between animal live weight and herbage mass per unit of area being grazed at any one time (the inverse of herbage allowance), an instantaneous measurement of the animal-to-herbage relationship (Allen et al., 2011). In WFM, however, the level of residual is an input to the model, and therefore it needs to be defined by the user at the beginning of the simulation. It is a minimum residual and cows are not allowed to graze below this level, but they may leave higher residuals behind if allowance exceeds requirements. In the model, cow movements to the next pasture occur independent of residuals by following a rotation policy. When cows leave a pasture after a grazing event, the actual residual (user-defined or above) is used as an input for the herbage model to predict regrowth rates. We know that residual level, in reality, is a product of the grazing pressure modulated by the interaction between the plant (sward structure) and the animal, and animals keep grazing down the pasture until they are moved to the next one. Because the actual residual from a grazing event in a particular pasture determines consequent regrowth rates for that pasture (Lee et al., 2008), user-defined residuals in WFM are an oversimplification of the effects of grazing pressure on herbage depletion, intake (Gregorini et al., 2011; Perez-Prieto and Delagarde, 2012, 2013), and resultant postgrazing growth rates.

Increasing grazing pressure accelerates herbage depletion and generally leads to lower residuals (Dillon, 2007; Gregorini et al., 2009; Perez-Prieto and Delagarde, 2013). Low residuals have been reported to stimulate growth of perennial ryegrass-dominated swards (Lee et al., 2007, 2008), but could be detrimental to the regrowth of other pasture species. Herbage yield is a key component of pasture-based dairy systems, and managing grazing pressure at different temporal scales (i.e., stocking density and rate) as it affects herbage yield is therefore an important issue. The challenge for WFM simulations is not only to predict dynamic changes in residual levels, but also herbage production at a farm level, considering the effects of grazing pressure. Consequently, the incorporation of a model considering plant-animal relationship and resultant level of herbage depletion into the WFM emerges as an option to cope with some of these challenges.

The main objective of the present work was to develop a new version of the WFM that predicts residuals instead of using user-defined residuals, thereby simulating related effects dynamically. This development required the incorporation of ConPast into the WFM.
ConPast is a component model representing plant-animal relationship for the estimation of herbage intake in grazing ruminants (Galli et al., 1999). The new version of the WFM, incorporating ConPast, was subjected to a sensitivity evaluation and also tested against experimental data from Macdonald et al. (2008), who reported the effect of stocking rate on herbage and animal production of dairy cows in pasture based-systems. This data set was previously used by Beukes et al. (2008) to evaluate the WFM and, therefore, helped to illustrate the adequacy and improvement of the new model development.

\section{MATERIALS AND METHODS}

\section{Models}

Details of the WFM and its capabilities have been previously described (Neil et al., 1999; Wastney et al., 2002; Beukes et al., 2008). In brief, in the WFM, animals and paddocks are represented by instances (individual replicates) of the cow and pasture models initialized for each age, breed, and other characteristics unique for each cow instance. Herbage growth and soil characteristics are unique for each paddock. The herbage growth model in the WFM (Romera et al., 2009) is climate-driven using weather data provided by the National Institute of Water and Atmospheric Research (Auckland, New Zealand) for the nearest weather station. A standard soil water balance is used to determine actual soil water content (Romera et al., 2010). Pasture growth responds to $\mathrm{N}$ fertilizer applied as either mineral fertilizer or irrigated effluent. Paddocks are grazed rotationally [under the strip-grazing method (24-h pastures strips)] and a particular herd (clusters of simulated cow instances) may take several days to graze all the strips of a paddock, depending on rotation length at the time. Rotation length is the time taken by the cows to graze (to rotate through) all the available paddocks on the farm, varying from $20 \mathrm{~d}$ in spring to $90 \mathrm{~d}$ in winter. Residuals are user-defined for 10-d time blocks through the year. The residual of a paddock is the minimum herbage mass cows are allowed to leave behind in the paddock. Paddocks can be eliminated from the grazing rotation for all or part of the year as part of a cropping regimen (e.g., maize, cereal, or brassica crops). Paddocks can be closed for conservation and cut for pasture silage according to user-defined settings for maximum allowable herbage mass and soil moisture conditions that allow harvesting machinery to enter the paddock. Supplements (homegrown or purchased) can be fed to cows according to policies created by the user. Chemical composition of herbage is a user setting and varies on a monthly basis. 
Other user-defined policies relate to cow management include breeding, grazing off the farm, pasture restriction periods, drying off, culling, and replacement.

ConPast is a day-step mechanistic and dynamic model that estimates herbage intake by grazing cattle (Galli et al., 1999). This model is an adaptation of the models from Ungar and Noy-Meir (1988), Laca and Demment (1991), and Laca et al. (1992). ConPast relates herbage intake rate to sward canopy structure. Sward variables [e.g., herbage biomass, height (taken as extender tiller length), bulk density of grazing layers, barriers to bite depth] are used to predict bite dimensions (area, depth, and mass), bite rate, and intake rate. ConPast also considers animal variables such as live weight, breed, frame, sex, maximum grazing time, and milk production level, which are dynamically provided by Molly through the WFM framework (Figure 1). Also through the WFM, Molly provides ConPast with potential DMI (feed demand), which is used to determine daily DMI. To estimate DMI, ConPast takes the minimum between the potential DMI and the DMI resulting from the product of intake rate (calculated using several ingestive variables) and daily grazing time, modulated by the available herbage mass. ConPast is based on the concept that in relatively homogenous swards, stripgrazed cattle graze down (deplete) available herbage in successive layers (Ungar and Ravid, 1999; Wade et al., 1989). Due to changes in vertical distribution of herbage mass through the sward canopy (as simulated by the WFM, described herein), ingestive variables, and consequently intake rate, are affected by the level of herbage depletion (Laca et al., 1992; Gregorini et al., 2011). The level of herbage depletion predicted by ConPast determines the standing green and dead herbage remaining after grazing. Herbage depletion does not include litter, which is defined as dead leaves falling onto the ground after leaf abscission. However, measured residuals in the field include litter. Therefore, the new WFM (WFM with ConPast incorporated) calculates residuals by summing standing green and dead remaining after grazing and litter mass provided by the herbage growth model. The decay process, equations, and litter dynamics are detailed in McCall and BishopHurley (2003). In brief, litter is generated by abscission of the senescent plant tissue and decays at a rate that is a function of soil moisture, rain, and temperature. Litter also disappears when animals trample it into the ground, proportional to the amount of herbage eaten during each grazing event.

Vertical distribution of herbage mass and quality per layer of the sward canopy varies throughout the year (Delagarde et al., 2000). The new WFM simulates the vertical distribution linking Molly, the herbage growth model, and ConPast (Figure 1). Herbage mass is de- scribed by 5 layers, each one with a specific height (in millimeters, taken as extender tiller length) and bulk density (kilograms of DM per millimeter per hectare). The 5 layers of the sward canopy comprise (1) the top half $(0.5),(2)$ top half of the remainder $(0.25),(3)$ top half of the remainder $(0.0625)$, (4) top half of the remainder (0.03125), and (5) the rest (0.03125). These layers are constant proportions of the sward canopy height (taken as extender tiller length) and represent the functional defoliation depth (i.e., bite depth), as when the sward canopy is relatively homogeneous (horizontal plane) and the area offered and time allocated to graze is restricted, cattle graze down available herbage in successive layers (Wade et al., 1989; Ungar and Ravid, 1999). The fourth and fifth layers are assumed to have the same height (taken as extender tiller length) and bulk density. Typically, but not necessarily, part of fourth and the whole of the fifth are inaccessible to cows [depending on sward height and if a barrier to depletion (e.g., representing thick pseudo-stem layer) is set]. Based on data from Delagarde et al. (2000), the average bulk density of the sward ( $\mathrm{D}$; equal to herbage mass divided by sward surface height) is modeled as fluctuating during the year (Figure 2), assuming a sine wave shape between a point in midspring and midautumn [22 $\times 0.6$ and $11 \times 0.6 \mathrm{~kg}$ of $\mathrm{DM} / \mathrm{mm}$ per hectare, respectively, 0.6 being a scalar for New Zealand (Delagarde et al., 2000) as herbage masses exceeded $7 \mathrm{t}$ in spring, which differs from the average herbage mass in New Zealand pastures at that time of year]. To represent changes in bulk density of particular layers, density is affected by a density-increase factor $(\mathbf{C})$. This factor is constant through the layers in any particular season, but fluctuates between seasons. Seasonal fluctuation of $\mathrm{C}$ is modeled as a sine wave between spring and fall (2.21 and 1.76 inflexion points, respectively). Then,

$$
\mathrm{D} 1=\text { Density layer } 1=T,
$$

Density layer $i=T \times C^{i-1}$, (for $\left.i=2,3,4\right)$, and

$$
\text { Density layer } 5=\text { Density layer } 4 \text {, }
$$

where $C$ equals density layer $(n)$ divided by density layer $(n-1)$. The top half density $(T)$ can be derived for any particular day of the year from $C$ and $D[t=8$ $\left.\times D /\left(C^{3}+C^{2}+2 C+4\right)\right]$, which is derived as

$$
\text { Total Mass }=\sum_{i=1}^{5} \text { Mass Per } \text { Layer }_{i}
$$

where total mass (per hectare) is the sum of each layer mass per hectare; 


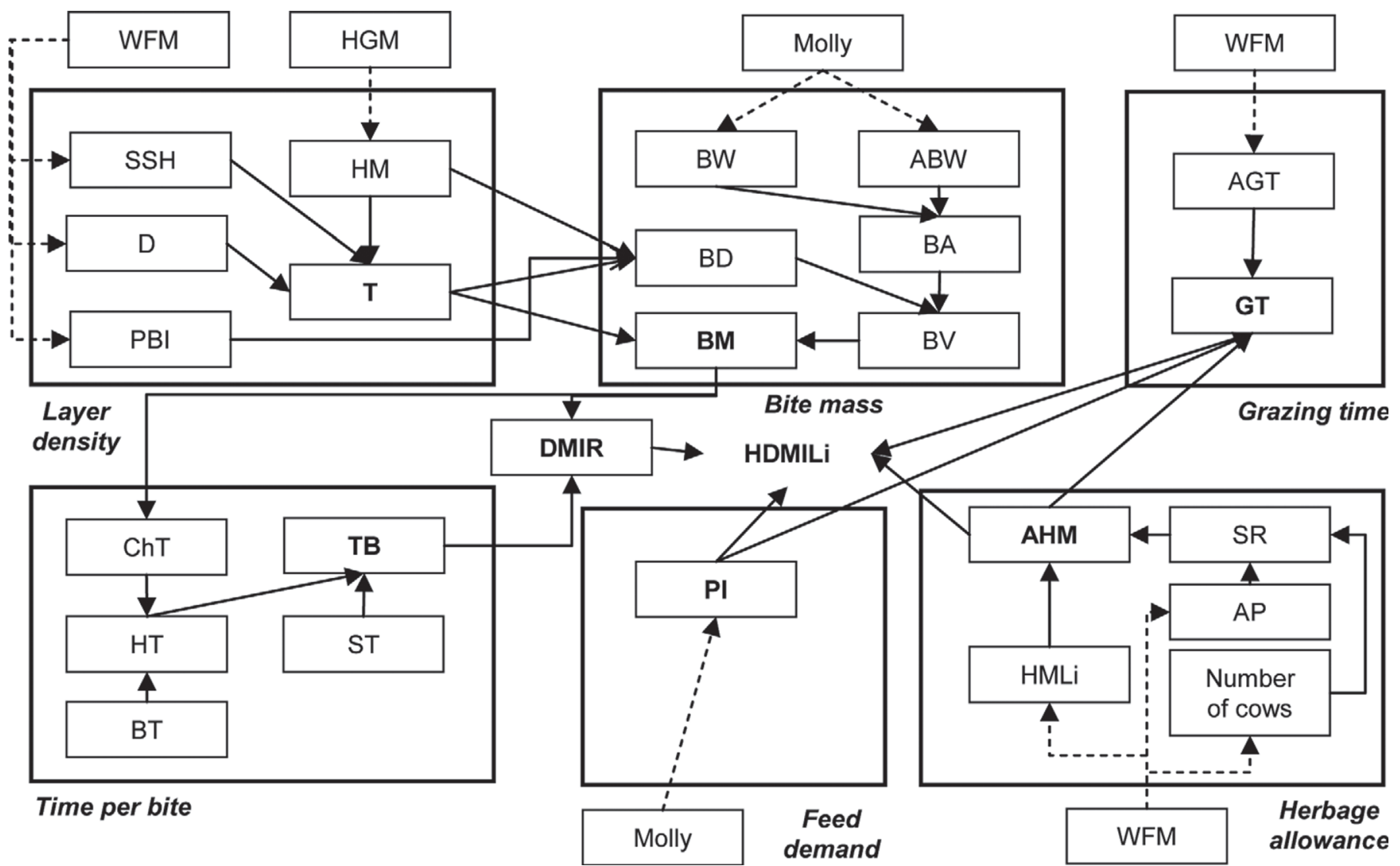

Figure 1. Simple schematic representation of the interaction between the DairyNZ whole-farm model (WFM; DairyNZ, Hamilton, New Zealand) and ConPast. (Solid arrows represent information flows within ConPast and dashed arrow represents information flows from WFM and its models to ConPast). WFM = whole farm model framework; HGM = herbage growth model; $\mathrm{SSH}=$ sward surface height; $\mathrm{T}=$ top half density of the sward canopy strata; PBI = physical barrier to ingestion; $\mathrm{D}=$ mean sward bulk density; $\mathrm{HM}=$ herbage mass; $\mathrm{BW}=$ live weight; $\mathrm{ABW}=$ adult live weight; $\mathrm{BD}=$ bite depth; $\mathrm{BA}=$ bite area; $\mathrm{BM}=$ bite mass; $\mathrm{BV}=$ bite volume; $\mathrm{GT}=$ grazing time; $\mathrm{AGT}=$ available grazing time; DMIR = DMI rate; HDMILi = herbage DMI from layer i; ChT = chewing time; $\mathrm{TB}=$ time per bite; $\mathrm{HT}=$ handling time; $\mathrm{ST}=$ search ing time; $\mathrm{BT}=$ biting time; $\mathrm{PI}=$ potential intake; $\mathrm{AHM}=$ available herbage mass; HMLi = herbage mass in layer $\mathrm{i}$; $\mathrm{AP}=$ area of daily strip to graze; and $\mathrm{SR}=$ stocking rate.

$$
\text { Total Mass }=\sum_{i=1}^{5} D_{i} \times H_{i}
$$

where total mass (per hectare) of each layer is density ( $\mathrm{kg}$ of $\mathrm{DM} / \mathrm{mm}$ per hectare) times its height $(H, \mathrm{~mm})$;

Total Mass (per ha) $=D_{1} \times H_{1}+D_{2} \times H_{2}+D_{3} \times H_{3}+$ $D_{4} \times H_{4}+D_{5} \times H_{5}$

Total Mass $($ per ha) $=T \times 1 / 2 H+T \times C \times 1 / 4 H+$ $T \times C^{2} \times 1 / 8 H+T \times C^{3} \times 1 / 16 H+T \times C^{3} \times 1 / 16 H ;$

Total Mass (per ha) $=T \times H$ $\left(1 / 2+1 / 4 C+1 / 8 C^{2}+1 / 16 C^{3}+1 / 16 C^{3}\right) ;$
Total Mass (per ha) $=\frac{T \times H}{8} \times C^{3}+C^{2}+2 C+4$; and

$$
T=\frac{8 \times D}{C^{3}+C^{2}+2 C+4} .
$$

Details of Molly and the herbage growth model used in the new WFM are described in Baldwin (1995) and Romera et al. (2009). The main equations of ConPast are described in Ungar and Noy-Meir (1988) and Laca and Demment (1991). Galli et al. (1999) described particularities of this adaptation.

\section{Virtual Experiments (Sensitivity Analysis)}

The sensitivity of the interaction between the current WFM and the ConPast model was evaluated through a 
a)

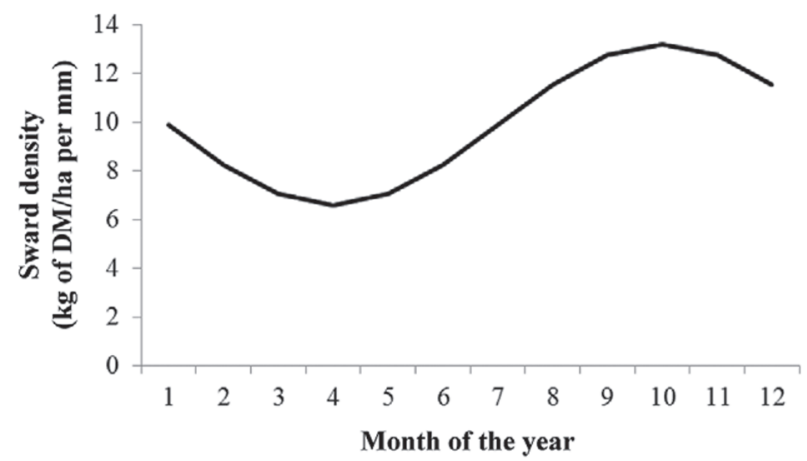

b)

March
gggg
gggg
gggg
gggg
gggg
gggg
gggg
gggg
gggg
gggg
gggg
gggg
gggg
gggg
gggg
gggg
gggg
gggg
gggggg
gggggg
ggggg
gggggg
gggggg
gggggg
gggggg
gggggg
gggggg
==gggggggggg
==gggggggggg
==gggggggggg
==gggggggggg
==gggggggggg
=====ggggggggggggggg
=====ggggggggggggggg
=====ggggggggggggggg
=====ggggggggggggggg

\section{June}

ggg

ggg

ggg

ggg

ggg

ggg

ggg

ggg

ggg

ggg

ggg

ggg

ggg

ggg

$\operatorname{ggg}$

ggg

ggg ggggg

ggg gggggg

ggg gggggg

ggg

ggggg

ggggg

ggggg

ggggg

ggggg

ggggg

ggggg

ggggg

ggggg

ggggg

ggggg

= gggggggg

= gggggggg

= gggggggg

= gggggggg

= gggggggg

$===$ ggggggggggggg

==== ggggggggggggg

==== ggggggggggggg

==== ggggggggggggg

==== ggggggggggggg

$===$ ggggggggggggg
September

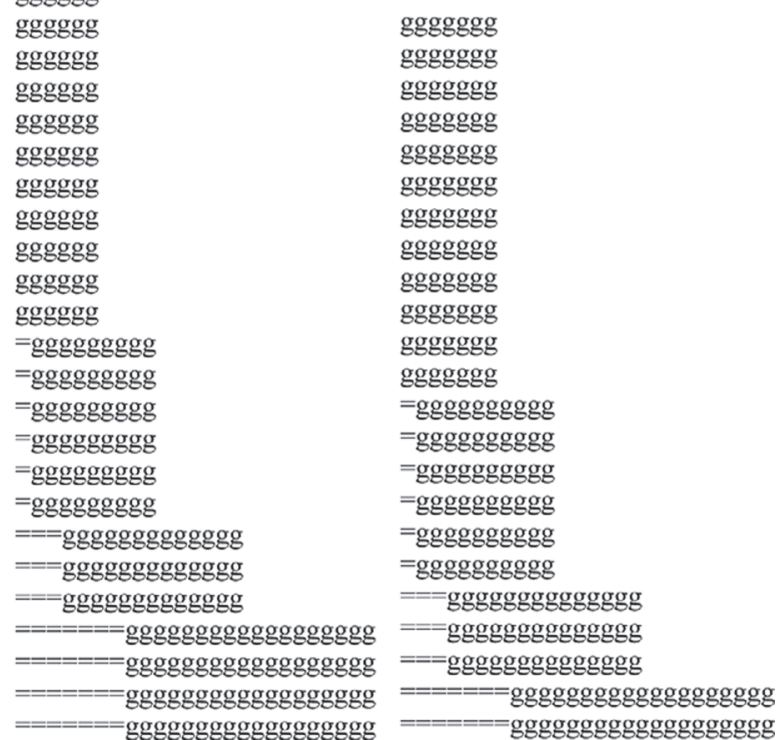

Figure 2. (a) Average bulk density of the sward ( $\mathrm{kg}$ of DM/ha and millimeter) modeled in the new version of the whole-farm method (WFM) as fluctuating throughout the year assuming a sine wave shape. Month of the year is represented as 1 for January, 2 for February, and so on. (b) Seasonal variation of density for different layers of the sward canopy as simulated in the new WFM. An equal sign represents dead herbage matter and $\mathrm{g}$ stands for green herbage matter. Herbage mass in these charts is 3,000 kg of DM/ha, including $500 \mathrm{~kg}$ of DM litter. Each row represents $10 \mathrm{~mm}$ of sward height and each character represents around (due to rounding) $10 \mathrm{~kg}$ of DM. 
series of virtual experiments. These experiments tested the main response laws of pertinent output variables to a range of selected input variables related to the introduction of ConPast in the new WFM. The new WFM was initialized to simulate 5 different feeding contexts: (a) 3 herbage allowances, 75,100 , and $125 \mathrm{~m}^{2} /$ cow per day, at an herbage mass of $3,000 \mathrm{~kg}$ of $\mathrm{DM} / \mathrm{ha}$ with a sward surface height of $30 \mathrm{~cm}$ and (b) the $100 \mathrm{~m}^{2} / \mathrm{cow}$ per day allowance with 2 different $\mathrm{C}$ (distributions of herbage mass though the vertical plane of the sward canopy). The model was run for 10 Holstein Friesian dairy cows (585 $\pm 47 \mathrm{~kg}$ of live weight and BCS $4.5 \pm 1$ at calving date), from 0 to 60 DIM, grazing a ryegrassdominated sward under strip-grazing (24-h pasture strip allocations). Model outputs were milk production, DMI, average herbage intake rate per day, daily grazing time, grazing efficiency, and residuals.

\section{Simulation Exercise (Validation)}

The new WFM was initialized to reproduce the treatments and management policies from the experiment of Macdonald et al. (2008). In brief, this experiment evaluated the effect of 5 stocking rates $(2.2,2.7,3.1,3.7$, and 4.3 cows/ha) on herbage production, milk production, and reproduction of dairy cows in pasture-based systems over 3 yr (1998-2001). Cows (aged $4.4 \pm 2.2 \mathrm{yr}$ with BW of $515 \pm 64.2 \mathrm{~kg}$, BCS of $4.4 \pm 0.61$, and EBV of $667 \pm 262.9$ ) were all seasonally calved (July $28 \pm$ $14 \mathrm{~d}$ ) and grazed a perennial ryegrass (Lolium perenne L.) and white clover (Trifolium repens L.) sward. Herbage chemical composition and nutritive values averaged $224 \mathrm{~g}$ of $\mathrm{CP} / \mathrm{kg}$ of DM, $429 \mathrm{~g}$ of NDF $/ \mathrm{kg}$ of DM, 106 $\mathrm{g}$ of $\mathrm{NSC} / \mathrm{kg}$ of $\mathrm{DM}, 78 \%$ OM digestibility, and 11.3 MJ of ME $/ \mathrm{kg}$ of DM. Differential management policies for each treatment included grazing interval (rotation length), supplementary feeding (type, amount, and criteria), mating, dry-off and culling criteria and dates, pasture fertilization (amount and timing), and conservation (dates and criteria). These policies were all managed according to a set of decision rules described in Macdonald and Penno (1998). Measurements included herbage pre- and postgrazing masses, herbage growth rate, herbage DMI, milk production and composition, and changes in BCS. Pasture herbage mass was estimated by 2 people by calibrated visual assessment of each paddock from a weekly farm walk, similar to the method described by O'Donovan et al. (2002). Herbage growth rate was calculated weekly from the increase in herbage mass on ungrazed paddocks. Herbage DMI was estimated individually using the n-alkane technique, as modified by Dillon and Stakelum (1989), and average DMI was calculated for each farmlet for 4 periods (seasons) of the year during which DMI was estimated. Milk production and composition of individual cow's milk were recorded weekly (Tru-Test milk meter system, Palmerston North, New Zealand). Milk fat, $\mathrm{CP}$, true protein, casein, and lactose concentrations were determined on composite afternoon and morning aliquot samples by Fossomatic FT120 (Foss Electric, Hillerød, Denmark). Body condition score was assessed pre- and postcalving on a 10-point scale, where 1 is emaciated and 10 is obese (Roche et al., 2004).

In the new WFM, each of 5 stocking rates farmlets of Macdonald et al. (2008) was developed by changing the area of the farm at a fixed number of cows, as in Macdonald et al. (2008). At the start of the simulations, cows were initialized based on age, BW, BCS, and genetic merit using production value (production value milk) according to Macdonald et al. (2008). Dates and number of days of the management policies presented by Macdonald et al. (2008) were averaged over the $3 \mathrm{yr}$ and set at the start of the simulation. All the simulation scenarios contained 15 pasture paddocks. Scenarios simulated 3 consecutive lactations over the term of 3 yr, also as in Macdonald et al. (2008).

\section{Statistical Evaluation}

Predicted values for residuals (monthly and average for the year), monthly herbage growth rate over a year, annual herbage yield, and annual herbage DMI per hectare were compared with observed values to assess the adequacy of the new WFM. The total number of data points for validation (average of $3 \mathrm{yr}$ ) of monthly residuals and herbage growth rates were 60 ( 5 stocking rates $\times 12 \mathrm{mo}$ ) and 5 (5 stocking rates) for pasture yield and DMI, respectively. This model assessment was conducted using the mean square prediction of error (MSPE), square root of MSPE (RMSPE) and MSPE decomposition, concordance correlation coefficient (CCC), mean absolute error (MAE), and relative prediction error $\{\mathbf{R P E}=\operatorname{RMSPE} /[\Sigma($ Observed $) / \mathrm{n}]$; Bibby and Toutenburg, 1977\}. Details and equations for the calculus of CCC and MAE are described in Tedeschi (2006). Accuracy is the model's ability to predict the right values and precision is the ability of the model to predict similar values consistently (Tedeschi, 2006). The RMSPE, mean bias, CCC, and RPE are measurements of model accuracy, whereas correlation coefficient is a measurement of model precision. The CCC is also known as reproducibility index, accounting simultaneously for accuracy and precision (Tedeschi, 2006). The closer the CCC is to 1 the more reproducible the model predictions; values of CCC between 0.65 and 0.8 and greater than 0.8 indicate moderate and substantial strength of the model, respectively. For models based on animal factors to predict intake values, RPE $<20 \%$ 
are considered accurate (Fuentes-Pila et al., 1996). The MSPE measures the distance between observed and predicted values, and its square root, RMSPE, is used to obtain the same units as the observed and predicted values. The RMSPE gives an estimation of the mean error amplitude, an RMSPE $<10 \%$ and between 10 and $20 \%$ of observed mean indicates satisfactory and acceptable predictions, respectively (Fuentes-Pila et al., 1996). This statistical evaluation of the new version of the WFM was compared with the evaluations of the current WFM presented by Beukes et al. (2008)

\section{RESULTS}

Results of the virtual experiments (sensitivity analysis) are presented graphically in Figure 3. Herbage allowance increased milk production and herbage DMI from 75 to $100 \mathrm{~m}^{2} /$ cow per day. Increments in herbage allowance from 100 to $125 \mathrm{~m}^{2} /$ cow per day had no effect on milk production and herbage DMI. Increments in herbage allowance increased the average instantaneous herbage intake rate and grazing time from 75 to 100 $\mathrm{m}^{2} /$ cow per day. The latter decreased from 100 to 125 $\mathrm{m}^{2} /$ cow per day. The level of residuals increased and the harvesting efficiency decreased as herbage allowance increased. At the same herbage mass and allowance, changes in the distribution of herbage DM through the vertical plane of the sward canopy did not affect milk production, herbage DMI, residual levels, and harvesting efficiency. However, these changes affected the instantaneous intake rate of herbage and daily grazing time. From $\mathrm{C}=1$ to $\mathrm{C}=2$, instantaneous herbage $\mathrm{DM}$ intake rate decreased, whereas grazing time increased.

Results of the simulation exercise or validation are presented in terms of monthly averages for residuals and herbage growth rate in Figure 4. Figure 5 presents annual averages of residuals, herbage production, and herbage intake. Statistical assessment of model predictions is presented in Table 1. The predicted patterns of monthly and mean annual postgrazing herbage mass (residuals) were very similar to the observed (Figures $4 \mathrm{a}$ and $5 \mathrm{a}$ ). Mean observed and predicted differed by less than $1 \%$.

The RMSPE for the monthly and mean annual residuals were 399 and $110 \mathrm{~kg}$ of $\mathrm{DM} / \mathrm{ha}$, whereas the RPE were 0.2 and 0.05 , respectively. The MAE for these predictions were 218 and $81 \mathrm{~kg}$ of DM/ha. The CCC averaged 0.79 for both variables.

Predicted herbage growth rate and annual production were also close to the observed (Figures $4 \mathrm{~b}$ and 5c). Mean observed and predicted differed by less than $3.5 \%$. The RMSPE were $11.5 \mathrm{~kg}$ of $\mathrm{DM} /$ ha per day and $531 \mathrm{~kg}$ of $\mathrm{DM} / \mathrm{ha}$, whereas the RPE were 0.23 and 0.02 , for herbage growth rate and annual production, respectively. The MAE for these predictions were $9 \mathrm{~kg}$ of DM/ha per day and $468 \mathrm{~kg}$ of DM/ha. The CCC averaged 0.76 for both variables.

Predicted means of herbage intake per hectare and per cow were approximately $3 \%$ greater than the observed means. Figure 5b shows observed and predicted values for annual herbage intake per cow and per hectare. The RMSPE were $692 \mathrm{~kg}$ of DM/ha per year and $169 \mathrm{~kg}$ of $\mathrm{DM} /$ cow per year, whereas the RPE were 0.04 and 0.03 for intake per hectare and per cow, respectively. The MAE for these predictions were $615 \mathrm{~kg}$ of DM/ ha per year and $153 \mathrm{~kg}$ of DM/cow per year. The CCC averaged 0.89 for both variables.

\section{DISCUSSION}

\section{Sensitivity of WFM and ConPast Interaction}

The results of the virtual experiments (Figure 3) indicate responses with the correct trends from the new WFM-ConPast model. The response in milk production, herbage DMI, herbage DMI rate, and grazing time to herbage allowance in the new WFM follows the shape and relative magnitude reported by Pérez-Prieto and Delagarde (2012) in a meta-analysis of the effect of pasture allowance on pasture intake, milk production, and grazing behavior of dairy cows grazing temperate grasslands, analyzing 56 publications from United Kingdom, New Zealand, Australia, Ireland, France, Korea, United States, Brazil, Finland, the Netherlands, and Argentina.

The reduction of residual levels and increase in harvesting efficiencies predicted by the new WFM in this sensitivity analysis (Figure 3) was a response to a decrease in herbage allowance followed the patterns previously reported for empirical data by RocaFernandez et al. (2011), who evaluated the effect of herbage allowance of perennial ryegrass swards on herbage DMI of Holstein-Friesian dairy cows. These new WFM prediction also agree with data presented by Dillon (2007) on postgrazing sward surface height and herbage utilization, as well as the seminal modeling of McCall et al. (1986) on the interdependence of animal intake, pre- and postgrazing pasture mass, and stocking density (i.e., herbage allowance).

Herbage intake rate is a function of the vertical DM distribution in the sward canopy. Thus sward canopies with low bulk densities in the upper layers would reduce intake rate and led to increments in grazing time as a compensatory mechanism to achieve daily DMI (Demment and Laca, 1994). At the same herbage mass and allowance, simulated changes in vertical distribution of the DM in the sward canopy (Figure 3) indicate a sensitive response on instantaneous intake rate and grazing 


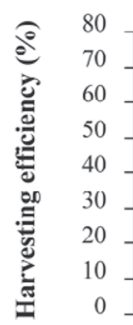

a)
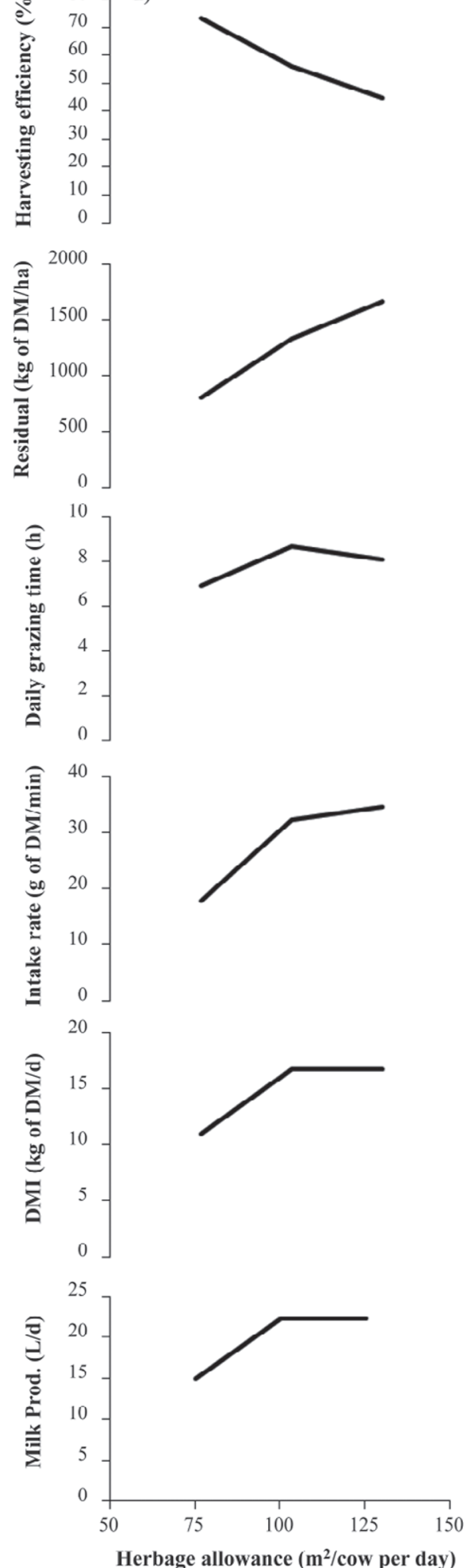

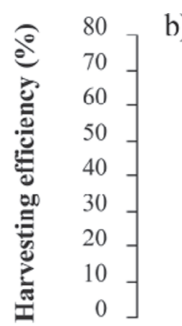

b)
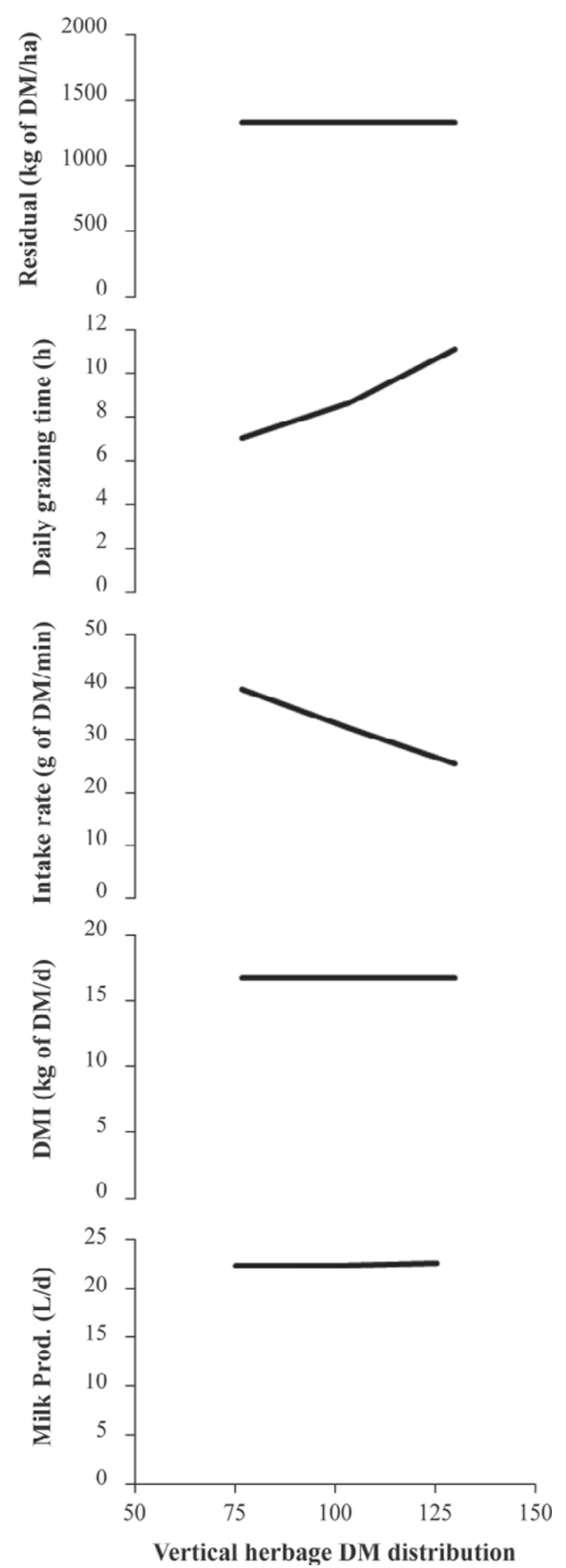

Figure 3. Effect of (a) herbage allowance and (b) herbage DM distribution on the vertical plane of the sward canopy on milk production

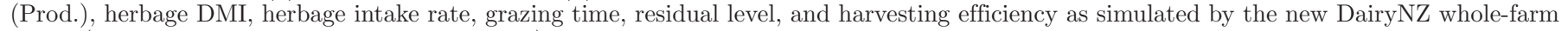

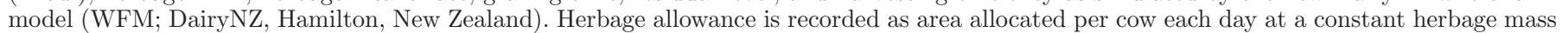

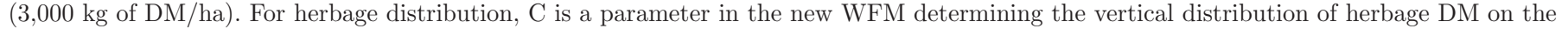

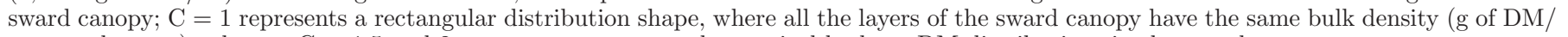
$\mathrm{mm}$ per hectare), whereas $\mathrm{C}=1.5$ and 2 represent nonrectangular vertical herbage DM distributions in the sward canopy. 

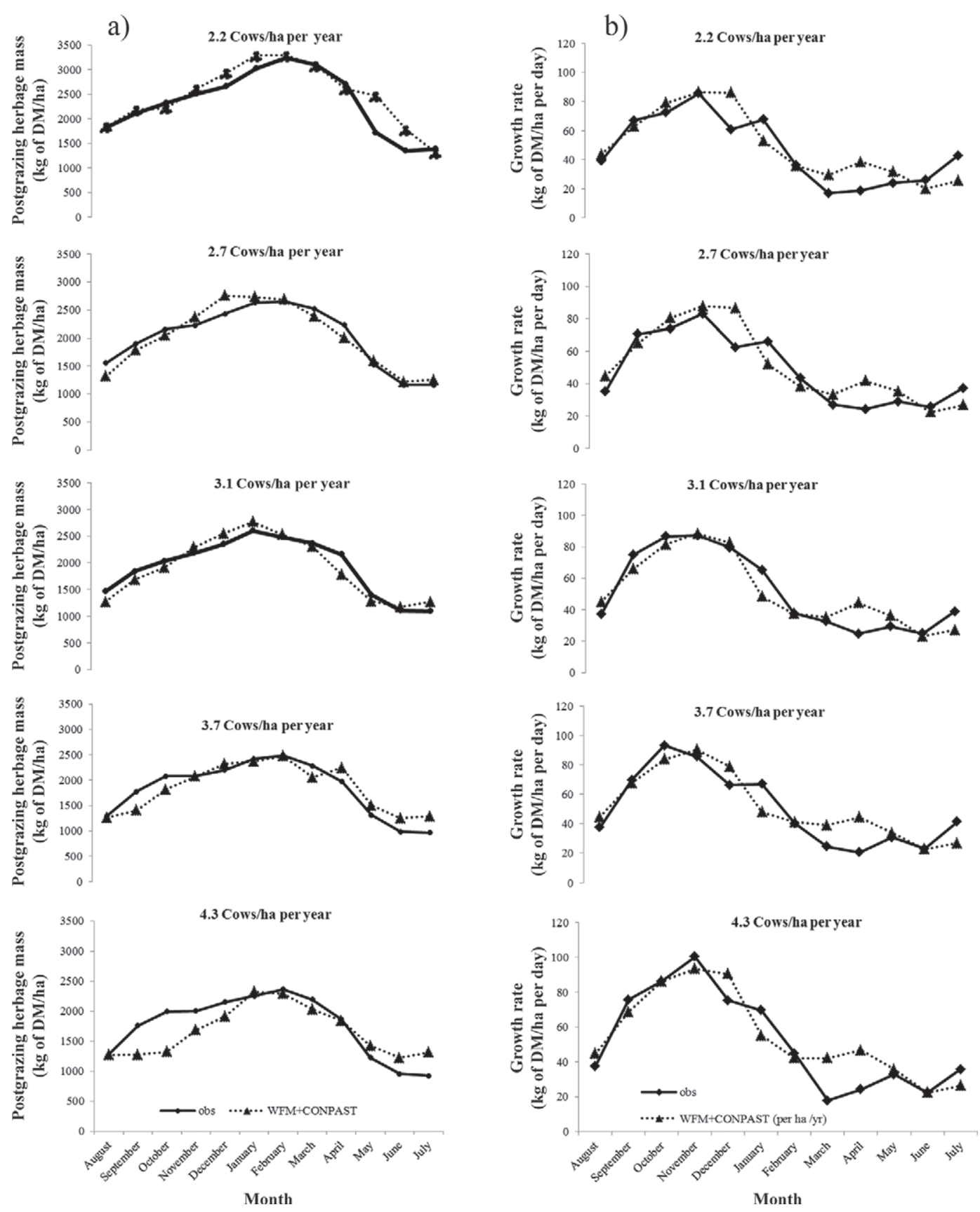

Figure 4. Effect of stocking rate on (a) postgrazing herbage mass (residuals) and (b) herbage growth rate as simulated by the new DairyNZ whole-farm model (WFM + ConPast; DairyNZ, Hamilton, New Zealand) versus observed (obs) data (Macdonald et al., 2008). Data presented are means of 3 consecutive lactations.

time, which agrees with previous reports of Laca et al. (1992), Gregorini et al. (2009a), and Fonseca et al. (2013).

\section{Model Validation}

The results presented (Table 1; Figures 4 and 5) indicate that the new WFM predicts monthly and mean annual residuals with acceptable accuracy and precision. The error of prediction fall within the range of residual standard deviations reported by L'Huillier and Thomson (1988), O'Donovan et al. (2002), and Stockdale and Kelly (1984) for pre- and postgrazing herbage mass estimated by double sampling procedure techniques (e.g., rising plate meter, pasture probe capacitance meter, and sward height). Moreover, monthly 


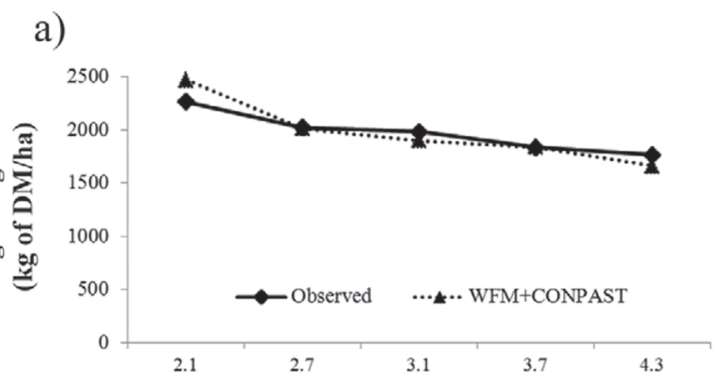

b)

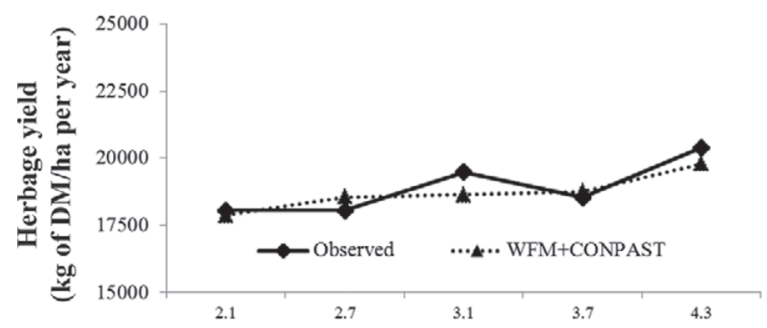

c)

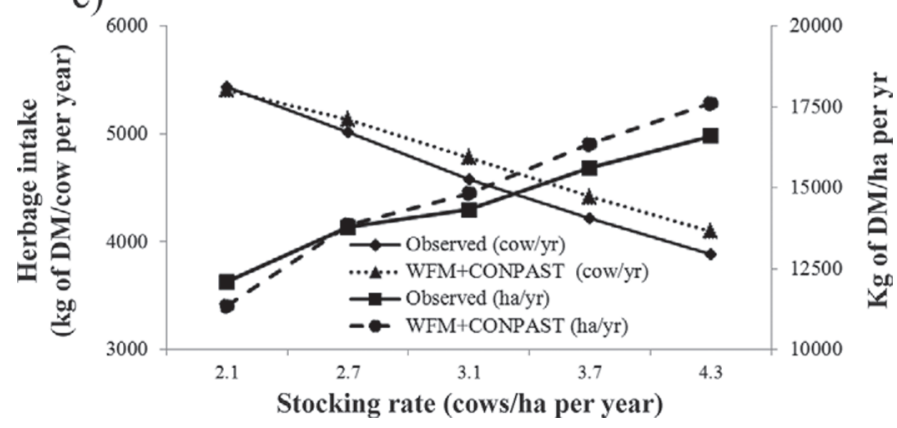

Figure 5. Effect of stocking rate on (a) mean annual postgrazing herbage mass (residual), (b) annual herbage yield, and (c) annual herbage intake as simulated by the new DairyNZ whole farm model (WFM + ConPast) versus observed data (Macdonald et al., 2008).

residuals were predicted with a very small line bias $(1.5 \%)$ and random error of $97.5 \%$, meaning not only a good structure of the model for this time scale, but also that the small lack of fit is simple random biological variation. It should be noted that the time scale of prediction selected could have had a smoothing effect on the actual accuracy of the model because random variations of predictions could have been compensated when cumulating week-to-week measurements. However, prediction of residuals is a step forward from previous published and evaluated versions of the WFM, which removes the need for the user to set residuals and increases the realism of WFM simulations. In other words, the simulated cows, rather than the user, decide the level of herbage depletion and residuals.

The increase in the realism of WFM simulations through dynamic and more mechanistic predictions of residuals improved WFM predictions of herbage growth

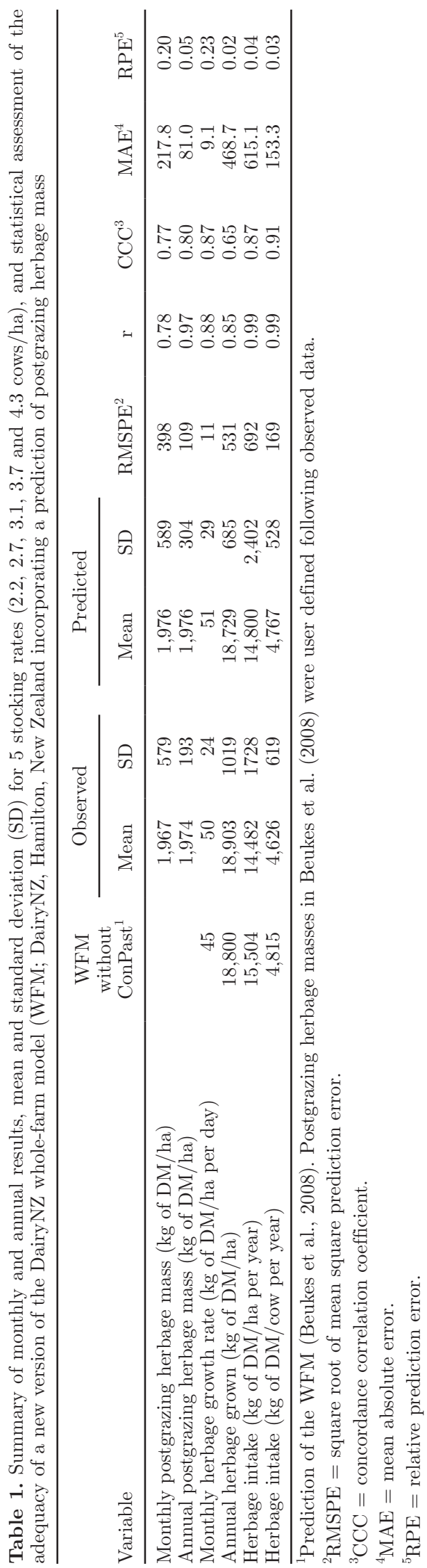

Journal of Dairy Science Vol. 97 No. 7, 2014 
rate and herbage grown per hectare and per year (Table 1). The new WFM was challenged to the same data set used by Beukes et al. (2008), who evaluated a previous version of the WFM with residuals set by the user following observed data. These authors reported a mean RPE of $37 \%$ for monthly predictions of herbage growth rate, whereas the new WFM predicted monthly herbage growth rates with substantial accuracy and precision and, thereby, reproducibility $(\mathrm{CCC}=0.87)$. Moreover, the new WFM predictions had minor line bias (2\%) and random error of $96 \%$, indicating the good structure of the model and that the prediction errors were mainly related to random biological variation. Beukes et al. (2008) reported a RMSPE of 3,000 $\mathrm{kg}$ of DM/ha and a RPE of $12 \%$ for annual herbage production. The new WFM predicted annual herbage production with considerably lower RMSPE (531 kg of DM/ha) and RPE $(2 \%)$ than the WFM evaluated by Beukes et al. (2008). The line bias was $11 \%$ and random error $80 \%$, which is evidence of the good structure of the model. The precision and accuracy of prediction of herbage growth by the new WFM is comparable and in some cases better than other herbage growth models evaluated under similar conditions in other parts of the world. For example, Barrett et al. (2004) compared the precision of 4 herbage growth models [Irish Brereton model (Brereton et al., 1996), LINGRA model (Schapendonk et al., 1998), and LINGRArep, the adapted version of LINGRA to account for reproductive growth and a version of the English model of Johnson and Thornley (1985)] and, using data from the location Hurley (England), the RMSPE ( $\mathrm{kg}$ of DM/ha) and line bias for these models were 18.9 and $0.09,34.5$ and $0.15,24.26$ and 0.18 , and 27.14 and 0.05, respectively. Later Barrett et al. (2005) evaluated the performance of a new herbage growth model (GrazeGro) against 9 seasons of growth in different regions of Europe (Spain, France, and the Netherlands) with similar characteristics to the New Zealand ryegrass-dominated swards. The mean RMSPE ( $\mathrm{kg}$ of $\mathrm{DM} / \mathrm{ha}$ ) and line bias for GrazeGro were 23 and 0.04, respectively. Therefore, this new development of the WFM and the resultant improvement in the prediction of herbage growth rate and production, allow for more realistic simulations of effects of grazing pressure on subsequent herbage production.

Previous studies indicated a positive relationship between stocking rate, grazing pressure, defoliation frequency and herbage growth rate, and total yield (Kristensen, 1988; Fales et al., 1995; Tuñon et al., 2013). For example, within a range of 2 and 3.2 cows/ ha, Fales et al. (1995) reported an increase of $480 \mathrm{~kg}$ of herbage DM/ha and per year per unit of increase in stocking rate (cow/hectare). Data from Macdonald et al. (2008) followed this pattern and suggested a posi- tive and linear relationship between herbage yield and stocking rate. Yield increased by $518 \mathrm{~kg}$ of herbage $\mathrm{DM} / \mathrm{ha}$ and per year per increment unit of stocking rate. The new WFM followed a very similar pattern, predicting an increase of $401 \mathrm{~kg}$ of herbage DM/ha and year per increment unit of stocking rate. Regressing the prediction error against predicted values gives a slope not significantly different from zero $(P=0.583)$, which indicates no difference between the observed and predicted rate of increase of herbage produced with increments in stocking rate. These results demonstrate the value of the present development and increased realism in the new WFM.

Macdonald et al. (2008) argued that the increase in herbage production with increments in stocking rate relates to a decrease in residuals, which reflects an increase in herbage utilization (herbage consumed per herbage produced). The new WFM predicted such a reduction in residuals (Figures $2 \mathrm{a}$ and 3a) and increment in herbage utilization with increments in stocking rate. Taking the simulated values of herbage grown and eaten per hectare for each stocking rate, herbage utilization increased by 0.11 per unit of increment in stocking rate $\left(\mathrm{y}=0.1169 \mathrm{x}+0.416, \mathrm{R}^{2}=0.93, \mathrm{SE}=\right.$ $0.02, P<0.05, \mathrm{n}=5)$. Reducing residuals by increasing pasture utilization removes dead material and litter, which prevents shading of tillers and stimulates growth (Lee et al., 2008). The new WFM predicted reductions in litter parallel to increments in stocking rate (Figure 4a). Reductions in litter parallel to increments in stocking rate were also observed, but not published, in the experiment of Macdonald et al. (2008). These results further support the value and realism of the new development in the WFM.

The statistical assessment of the new WFM also indicates that predictions of herbage intake per cow and per hectare are accurate and precise (Table 1). The level of accuracy and precision of the new WFM predictions are within the ranges reported for other models of herbage intake and milk production of grazing dairy cows. For example, GrazeIn, the comprehensive model of Delagarde et al. (2011), the empirical models of Fuentes-Pila et al. (1996) and Shah and Murphy (2006), and a semiempirical model of Gregorini et al. (2009b). Fuentes-Pila et al. (1996) considered a RPE $<10 \%$ satisfactory for prediction of DMI; whereas, based on Shah and Murphy (2006), the RMSPE of the new WFM indicates a satisfactory accuracy of prediction. It must be noted that the time scale of prediction selected could have had smoothing effect on the actual accuracy of the model. However, due to the independence of the data used for the new WFM validation, this is a major improvement from the version evaluated by Beukes et al. (2008). The new WFM predicts annual 
herbage intake per cow with half of the RMSPE and an RPE 4 times smaller than those reported by Beukes et al. (2008). This improvement also illustrates the importance of representing animal-to-herbage relationship, even at the scale of farm systems management. Ultimately, herbage intake is the most important variable determining animal productive performance in pastoral systems (Kolver and Muller, 1998).

\section{CONCLUSIONS}

Incorporating a model considering plant-animal relationship and resultant herbage depletion into the WFM allows for more mechanistic and dynamic prediction of herbage growth, herbage DMI, and residuals. Although the new WFM has the biological basis and mechanistic structure to simulate feeding scenarios as supplements are fed to animals, responses in herbage depletion to supplementary feeding have not yet been validated. This model development, however, has been evaluated against trial data coming from a $100 \%$ pastoral grazing systems, and demonstrated acceptable behavior when predictions were compared with observations. Therefore, more realistic simulations of the effect of grazing management (e.g., stocking rate, stocking density, herbage allowance, and defoliation frequency) on herbage production and intake can be achieved without intervention from the model user.

\section{ACKNOWLEDGMENTS}

This work was funded by New Zealand dairy farmers through DairyNZ Inc. (Hamilton, New Zealand). The authors thank Claudia Kamphuis (Wageningen University, Wageningen, the Netherlands) and Sharon Woodward (DairyNZ) for reviewing this work and manuscript, and Hemda Levy (DairyNZ) for her coding part of this model development.

\section{REFERENCES}

Allen, V., C. Batello, E. Berretta, J. Hodgson, M. Kothmann, X. Li, J. McIvor, J. Milne, C. Morris, and A. Peeters. 2011. An international terminology for grazing lands and grazing animals. Grass Forage Sci. $66: 2-28$.

Baldwin, R. L. 1995. Modeling Ruminant Digestion and Metabolism. Springer, New York, NY.

Barrett, P. D., A. S. Laidlaw, and C. S. Mayne. 2004. An evaluation of selected perennial ryegrass growth models for development and integration into a pasture management decision support system. J. Agric. Sci. 142:327-334.

Barrett, P. D., A. S. Laidlawb, and C. S. Maynea. 2005. GrazeGro: A European herbage growth model to predict pasture production in perennial ryegrass swards for decision support. Eur. J. Agron. $23: 37-56$.

Beukes, P. D., C. Palliser, K. Macdonald, J. Lancaster, G. Levy, B. Thorrold, and M. Wastney. 2008. Evaluation of a whole-farm model for pasture-based dairy systems. J. Dairy Sci. 91:2353-2360.
Bibby, J., and H. Toutenburg. 1977. Prediction and Improved Estimation in Linear Models. Wiley, New York, NY.

Brereton, A. J., S. A. Danielov, and D. Scott. 1996. Agrometeorology of grass and grasslands for middle latitudes. Technical Note No. 197. World Meteorological Organisation, Geneva, Switzerland.

Delagarde, R., J. Peyraud, L. Delaby, and P. Faverdin. 2000. Vertical distribution of biomass, chemical composition and pepsin-cellulose digestibility in a perennial ryegrass sward: Interaction with month of year, regrowth age and time of day. Anim. Feed Sci. Technol. 84:49-68

Delagarde, R., H. Valk, C. S. Mayne, A. J. Rook, A. González-Rodríguez, C. Baratte, P. Faverdin, and J. L. Peyraud. 2011. GrazeIn: A model of herbage intake and milk production for grazing dairy cows. 3. Simulations and external validation of the model. Grass Forage Sci. 66:61-77.

Demment, M. W., and E. A. Laca. 1994. Reductionism and synthesis in the grazing sciences: Models and experiments. Proc. Aust. Soc. Anim. Prod. 20:6-16.

Dillon, P. 2007. Achieving high dry-matter intake from pasture with grazing dairy cows. Pages 1-26 in Fresh Herbage for Dairy Cattle. A. Elersma, J. Dijkstra, and S. Tamminga, ed. Springer, Houten, the Netherlands.

Dillon, P., and G. Stakelum. 1989. Herbage and dosed alkanes as a grass measurement technique for dairy cows. Isr. J. Agric. Res. $28: 104$.

Fales, S., L. Muller, S. Ford, M. O’Sullivan, R. Hoover, L. Holden, L. Lanyon, and D. Buckmaster. 1995. Stocking rate affects production and profitability in a rotationally grazed pasture system. J. Prod. Agric. 8:88-96.

Fonseca, L., P. C. F. Carvalho, J. C. Mezzalira, C. Bremm, J. R. Galli, and P. Gregorini. 2013. Effect of sward surface height and level of herbage depletion on bite features of cattle grazing Sorghum bicolor swards. J. Anim. Sci. 91:4357-4365. http://dx.doi. org/10.2527/jas.2012-5602.

Fuentes-Pila, J., M. DeLorenzo, D. Beede, C. Staples, and J. Holter. 1996. Evaluation of equations based on animal factors to predict intake of lactating Holstein cows. J. Dairy Sci. 79:1562-1571.

Galli, J. R., C. A. Cangiano, and H. H. Fernandez. 1999. Un modelo de simulacion del comportamiento ingestivo y consumo de bovinos en pastoreo. Pages 67-106 in ConPast 3.0 Programa de Computacion para la Estimacion del Consumo de Bovinos en Pastoreso. La Barrosa, Buenos Aires, Argentina.

Gregorini, P., S. Gunter, M. Bowman, J. Caldwell, C. Masino, W Coblentz, and P. Beck. 2011. Effect of herbage depletion on shortterm foraging dynamics and diet quality of steers grazing wheat pastures. J. Anim. Sci. 89:3824-3830.

Gregorini, P., S. A. Gunter, P. A. Beck, J. Caldwell, M. T. Bowman, and W. K. Coblentz. 2009a. Short-term foraging dynamics of cattle grazing swards with different canopy structures. J. Anim. Sci. 87:3817-3824.

Gregorini, P., A. Romera, P. Beukes, J. Rossi, and K. MacDonald. 2009b. Using an existing intake model to demonstrate relationships between herbage allowance, hunger drive, days in milk and actual intake in grazing dairy cows. Proc. N. Z. Soc. Anim. Prod. $69: 27-31$.

Johnson, I. A., and J. H. M. Thornley. 1985. Dynamic model of the response of the vegetative grass crop to light, temperature and nitrogen. Plant Cell Environ. 8:485-499.

Kolver, E. S., and L. Muller. 1998. Performance and nutrient intake of high producing Holstein cows consuming pasture or a total mixed ration. J. Dairy Sci. 81:1403-1411.

Kristensen, E. S. 1988. Influence of defoliation regime on herbage production and characteristics of intake by dairy cows as affected by grazing intensity. Grass Forage Sci. 43:239-251.

L'Huillier, P., and N. Thomson. 1988. Estimation of herbage mass in ryegrass/white clover dairy pastures. Proc. N. Z. Grassl. Assoc. 49:117-122.

Laca, E., and M. Demment. 1991. Herbivory: The dilemma of foraging in a spatially heterogeneous food environment. Pages 30-44 in Plant Defenses Against Mammalian Herbivory. CRC Press, Boca Raton, FL. 
Laca, E., E. Ungar, N. Seligman, and M. Demment. 1992. Effects of sward height and bulk density on bite dimensions of cattle grazing homogeneous swards. Grass Forage Sci. 47:91-102.

Lee, J., D. Donaghy, and J. Roche. 2007. The effect of grazing severity and fertilizer application during winter on herbage regrowth and quality of perennial ryegrass (Lolium perenne L.). Anim. Prod. Sci. 47:825-832.

Lee, J., D. Donaghy, and J. Roche. 2008. Effect of defoliation severity on regrowth and nutritive value of perennial ryegrass dominant swards. Agron. J. 100:308-314.

Macdonald, K. A., and J. Penno. 1998. Management decision rules to optimise milk solids production on dairy farms. Proc. N.Z. Soc. Anim. Prod. 58:132-135.

Macdonald, K. A., J. Penno, J. Lancaster, and J. Roche. 2008. Effect of stocking rate on pasture production, milk production, and reproduction of dairy cows in pasture-based systems. J. Dairy Sci. $91: 2151-2163$

McCall, D. G., and G. Bishop-Hurley. 2003. A pasture growth model for use in a whole-farm dairy production model. Agric. Syst. 76:1183-1205.

McCall, D. G., R. J. Townsley, J. S. Bircham, and G. W. Sheath. 1986. The interdependence of animal intake, pre-and post-grazing pasture mass and stocking density. Proc. N. Z. Grassl. Assoc. 47:255-261.

Neil, P., R. Sherlock, and K. Bright. 1999. Integration of legacy subsystem components into an object-oriented simulation model of a complete pastoral dairy farm. Environ. Model. Softw. 14:495-502.

O'Donovan, M., P. Dillon, M. Rath, and G. Stakelum. 2002. A comparison of four methods of herbage mass estimation. Ir. J. Agric. Food Res. 41:17-27.

Pérez-Prieto, L., and R. Delagarde. 2012. Meta-analysis of the effect of pregrazing pasture mass on pasture intake, milk production, and grazing behavior of dairy cows strip-grazing temperate grasslands. J. Dairy Sci. 95:5317-5330.

Pérez-Prieto, L., and R. Delagarde. 2013. Meta-analysis of the effect of pasture allowance on pasture intake, milk production, and grazing behavior of dairy cows grazing temperate grasslands. J. Dairy Sci. 96:6671-6689

Roca-Fernandez, A. I., M. A. O'Donovan, J. Curran, and A. Gonzalez-Rodriguez. 2011. Effect of pre-grazing herbage mass and daily herbage allowance on perennial ryegrass swards structure, pasture dry matter intake and milk performance of Holstein-Friesian dairy cows. Span. J. Agric. Res. 9:86-99.
Roche, J. R., P. G. Dillon, C. R. Stockdale, L. H. Baumgard, and M. J. VanBaale. 2004. Relationships among international body condition scoring systems. J. Dairy Sci. 87:3076-3079.

Romera, A., P. Beukes, C. Clark, D. Clark, H. Levy, and A. Tait. 2010. Use of a pasture growth model to estimate herbage mass at a paddock scale and assist management on dairy farms. Comput. Electron. Agric. 74:66-72.

Romera, A. J., D. McCall, J. Lee, and M. Agnusdei. 2009. Improving the McCall herbage growth model. N. Z. J. Agric. Res. 52:477494.

Schapendonk, A. H. M., C. W. Stol, D. W. G. Van Kraalingen, and B. A. M. Bouman. 1998. LINGRA, a source/sink model to simulate grassland productivity in Europe. Eur. J. Agron. 9:87-100.

Shah, M. A., and M. R. Murphy. 2006. Development and evaluation of models to predict the feed intake of dairy cows in early lactation. J. Dairy Sci. 89:294-306.

Stockdale, C., and K. Kelly. 1984. A comparison of a rising plate meter and an electronic capacitance meter for estimating the yield of pastures grazed by dairy cows. Grass Forage Sci. 39:391-394.

Tedeschi, L. O. 2006. Assessment of the adequacy of mathematical models. Agric. Syst. 89:225-247.

Tuñon, G., E. Kennedy, B. Horan, D. Hennessy, N. Lopez Villalobos, P. Kemp, A. Brennan, and M. O'Donovan. 2013. Effect of grazing severity on perennial ryegrass herbage production and sward structural characteristics throughout an entire grazing season. Grass Forage Sci. 69:104-118. http://dx.doi.org/10.1111/gfs.12048.

Ungar, E., and I. Noy-Meir. 1988. Herbage intake in relation to availability and sward structure: grazing processes and optimal foraging. J. Appl. Ecol. 25:1045-1062.

Ungar, E., and N. Ravid. 1999. Bite horizons and dimensions for cattle grazing herbage to high levels of depletion. Grass Forage Sci. 54:357-364

Wade, M., J. Peyraud, G. Lemaire, and E. Comeron. 1989. The dynamics of daily area and depth of grazing and herbage intake of cows in a five day paddock system. Pages 1111-1112 in Proc. 16th Int. Grassl. Cong., Nice, France. Association Française pour la Production Fourragère (AFPF), Versailles, France.

Wastney, M., C. Palliser, J. Lile, K. Macdonald, J. Penno, and K. Bright. 2002. A whole-farm model applied to a dairy system. Proc. N.Z. Soc. Anim. Prod. 62:120-123. 